INTERNATIONAL JOURNAL OF MULTIDISCIPLINARY RESEARCH AND ANALYSis

ISSN(print): 2643-9840, ISSN(online): 2643-9875

Volume 04 Issue 06 June 2021

DOI: 10.47191/ijmra/v4-i6-02, Impact Factor: 6.072

Page No.- 692-698

\title{
Perception of Patients on Usage of Smartphones by Health Care Professionals during Clinic Hours
}

\author{
Samuel O Bolarinde. (PhD Ibadan) ${ }^{1}$, Odunola B. Olasoji (BMR.PT. Ife) ${ }^{2}$, Ibidunmoye O. Daniel (BMR.PT. \\ Ife) ${ }^{3}$ \\ 1,2Physiotherapy Department, Federal Medical Centre, Owo, Ondo - State. Nigeria. \\ ${ }^{3}$ Physiotherapy Department, Federal Medical Centre, Ido-Ekiti, Ekiti- State. Nigeria.
}

\begin{abstract}
Background of the study: Smartphones medically related applications are quickly becoming one of the main tools for accessing clinical information among health care professionals.

Aim of Study: This study assessed the perception of patients on usage of smartphones by health care professionals during clinic hours.

Methodology: The study recruited 185 patients. Data on demographic characteristics and perception of patients on the use of smartphones for medical information were obtained using a self-administered questionnaire. Data were summarized using a descriptive statistics and inferential statistics of Chi square. Alpha level was set at 0.005

Results: 76 Males, 109 Females participated in this study. 67.6\% (125) own a smartphones. 34.6\% (64) have seen health care professionals using smartphones during clinic hours, $28.1 \%$ (18) had their health care providers explain to them reasons for using smartphone. 34.1\% (63) agreed it was unprofessional for health care provider to use smartphone during clinic, 33.5\% (62) disagreed, $32.4 \%(60)$ were undecided. No association observed between respondents' age $(\chi 2=12.00, p=0.606)$, educational qualification $(\chi 2=8.501, p=0.075)$ and responses to the statement that use of smartphones by health care professional was unprofessional.

Conclusion: Although one third of the respondents agreed that usage of smartphones by healthcare professionals in the clinic while attending to patients was unprofessional however, usage of smartphone for health related information by health care professionals during clinic hours should be with caution to avoid losing the confidence repose in them by their patients.
\end{abstract}

KEYWORDS: Smartphones, Application, Health Care Information, Patients

\section{INTRODUCTION}

Smartphones are the most popular and portable hand-held mobile communication devices in recent times that has replace the former feature phones. The global success recorded in smartphones industries was triggered by the implementation of built-in applications (apps), self-contained software pieces created for specific aims. ${ }^{1}$

The usage of smartphones among the general population has since grown exponentially, fueling an explosive proliferation of mobile health interventions application (apps). ${ }^{2}$ These smartphones applications are increasingly deployed in clinical settings to augment patient education, communication, monitoring, and chronic disease management. ${ }^{3}$ There are currently thousands of commercial smartphone medical apps designed to support health management in facilitating point-of-care decisions such as drug dosing by presenting relevant information in an aggregated and easily graspable format. ${ }^{4,5}$ These apps assist in providing evidencebased, patient-centered care while decreasing error rates and face increasing popularity among healthcare professionals worldwide. ${ }^{5-8}$

Studies have showed that greater proportions of health care professionals report using some form of portable hand-held, networkenabled electronic device such as smartphones in the workplace, contributing to the rapid growth in medical apps, which appears to be the third fastest-growing app category on the market. ${ }^{10}$ The usage of smartphones' medical apps in health care settings is therefore not a passing trend but rather a practice that is now highly integrated into the work culture, which is likely to expand and grow in the future. ${ }^{11}$ 


\section{Perception of Patients on Usage of Smartphones by Health Care Professionals during Clinic Hours}

Smartphones' medical apps are generally considered to be of value to patients and health care providers in the form of speed of information transmission, clinical decision making, and accessibility. ${ }^{10,12}$ Although several studies have explored patient attitudes toward health technology and their impact on the patient-provider relationship. The results from these studies indicated that most patients did not express a negative attitude toward their health care providers' use of such technology. ${ }^{13-15}$

In Nigeria, more than sixty percent of adults' population own a smartphone and are at various time search for information on health, therefore, they are likely to know of the potentials of the use of smartphone in medical education. They are, however, unlikely to be aware of the availability of applications specific to educating and assisting medical professionals in case evaluation and diagnosis. Therefore, patients may perceive the use of a smartphone by the doctor as distraction thereby decreasing the level of trust in the relationship and harming the development of a good rapport.

Many patients are of older age and it is known that the prevalence of smartphone ownership is considerably lower among this age group. These patients are, therefore, those most at risk of misperceiving the use of smartphones by doctors and experiencing damage to the doctor-patient relationship. ${ }^{16}$

Previous researchers in other part of the world have investigated the use of smartphones among medical students and doctor populations to enhance educational and improve patients care. Patient attitudes toward health technology and their impact on the patient-provider relationship has also been investigated, however, the perception of patients on the use of smartphones by health care professionals for health care information particularly during clinic hours seems not to have been investigated in this environment. This study was therefore designed to investigate patients' perception of the use of smartphones by health care professionals during clinic hours in a Nigeria tertiary health facility.

\section{METHODOLOGY}

The cross-sectional study recruited 185 patients from various outpatient clinics of two purposely selected Federal Hospitals in Ondo and Ekiti State in South-western Nigeria. The study protocol was approved by the Health Research Ethics Committee of Federal Medical Centre, Owo (FMC/OW/380/LXX1/174). Patients inform consent was sought and obtained before the recruitment of participants. The survey instrument for the study was a self-administered questionnaire that sought information on demographic characteristics of patients and perception on the use of smartphones by health care professional during clinic hours. Data analysis was done using Statistical Package for Social Science (SPSS) version 20.0 software. Data were summarized using a descriptive statistics of percentage and frequency distribution. Inferential statistics of Chi square was used to test for association between variables. Alpha level was set at 0.005 .

\section{RESULTS}

A total of 185 patients participated in this study. $76(41.1 \%)$ were males while $109(58.9 \%)$ were females. $125(67.6 \%)$ of the participants were married, $42(22.7 \%)$ single, $15(8.1 \%)$ widow while $3(1.6 \%)$ were widower. Ages $26-35$ are the participants ages with the highest frequency (26.5\%), followed by $36-45$ age group (16.8\%), ages 16-25 (15.1\%), 46 - 55 and 66-75 (13.5\%), while ages $86-95(1.1 \%)$ was the least. Majority of the participants $(61.6 \%)$ had tertiary education, $22.7 \%$ had secondary education while only $15.7 \%$ had primary education. Participants from the medical outpatient clinic were in the majority $(27.0 \%)$, followed by physiotherapy outpatient (22.7\%), ophthalmology outpatient (16.8\%), Surgical outpatient (14.1\%) orthopaedic outpatient (13.5\%) while obstetrics/gynaecology was the least (5.9\%). The demographic characteristics is presented in figure 1.

Table 2 showed the perception of respondents on the use of smartphones for medical related information by health care workers. The result showed that, $67.6 \%$ (125) of the respondents own a smartphones while $32.4 \%(60)$ did not. 67 (32.6\%) of the respondents had search for health related information using smartphones while 121 (65.4\%) had never done so. Only 34.6\% (64) have seen health care professionals using smartphones while attending to them in the clinic however, $28.1 \%$ (18) submitted that, their health care providers explained to them reasons for using smartphone while attending to patients in the clinic.

The result revealed that majority of the respondents (78.9\%) agreed that smartphones can be helpful in patients' care, $66.2 \%$ accepted that various smartphones apps are available and useful in patients' care. The results showed that, $34.1 \%(63)$ of the respondents agreed that it was unprofessional for health care provider to use smartphone during clinic while $33.5 \%$ (62) disagreed however, $32.4 \%(60)$ were undecided. Furthermore, $21.1 \%$ (39) agreed that "usage of smartphones during clinic is an indication that the user does not know what to do", 27.6\% (51) were undecided while $51.4 \%$ (95) disagreed. Findings from this study showed that $23.2 \%$ (43) of the respondents felt they could not entrust their health care to a provider who uses smartphone while attending to patients due to lack of confidence while $56.2 \%$ (104) disagreed, $20.5 \%$ (38) were however undecided.

Table 3 showed the level of association between respondents' age, educational qualification and responses to "usage of smartphones by health care professional was unprofessional. The result showed that, there was no association between respondents' age $(\chi 2=12.00, p=0.606)$, educational qualification $(x 2=8.501, p=0.075)$ and responses to the statement that use 


\section{Perception of Patients on Usage of Smartphones by Health Care Professionals during Clinic Hours}

of smartphones by health care professional was unprofessional. The bar charts showing the distribution of responses to usage of smartphone during clinic according to the age group and educational qualification is presented in Figure 1 and 2 respectively.

\section{DISCUSSIONS}

This study was conducted to investigate the perceptions of patients on the use of smartphones for medical information among health care providers. The study found that majority of the patients own a smartphones, this could be attributed to the fact that smartphones are the most common mobile phones available in the market nowadays, the possibility of performing many functions such as keeping records of clinic attendance, availability of various downloadable medical apps for health information. This result is however in line with findings from previous studies where majority of patients were found to have smartphones. ${ }^{16,17}$

The result of the present study revealed that majority of the patients has used their smartphones to search for health related information at one point in time. This findings is an indication that, the patients are aware of possibilities of getting health information about their health status furthermore, majority (61.6\%) of the patients are educated at the tertiary level which probably had exposed them to the use of smartphones for information through the internet. This findings however is similar to the findings of Alvin Chan et al., ${ }^{18}$ they found that most patients had consistently used smartphone health apps to manage disease, reach a desired fitness goal, or improve health behaviors and considered health apps to be essential, medically necessary tools for tracking health conditions.

One third of the patients that participated in this study opined to have seen their health care providers searching for information on smartphones while attending to them in the clinic. This concur with findings of Alameddine et al., ${ }^{19}$ where close to three quarters of the respondents opined that physicians use their mobile devices in health care settings to access medical information and send or receive medical documents. Findings from this study also showed that, greater proportion of the patients agreed that smartphones could be helpful in patients' care as they are aware of the availability of various smartphone medical related apps. This showed that patients in the present study had clear views on the use of mobile devices, with the majority (78.9\%) stating that smartphones can greatly help in patients' care. This result supported the findings of previous researchers that, the use of technology in health care is considered to enhance communication and quality of health care. ${ }^{15,20,21}$ Hossain et al, ${ }^{15}$ reported that majority of patients were aware that smartphones could be used for general health/fitness tracking, obtaining health information, and appointment management similarly, Alameddine et al., ${ }^{19}$ concluded that majority of patients (92.6\%) recognize the important role of mobile devices in health care delivery and patient care.

The result of this study revealed that two third believed that usage of smartphone did not constitute unprofessionalism. This result corroborated the findings of Alameddine et al., ${ }^{19}$ that about two thirds of respondents reported that the use of mobile devices does not demonstrate a lack of professionalism or a breach of confidential patient information. The present study also showed that, the remaining one third of the patients are of the opinion that it was unprofessional of any health care professionals to be using smartphones for whatever reasons while attending to patients in the clinic. This findings suggest that the health care providers were visible to patients while using their smartphones. The reason for this opinion by the patients may be attributed to lack of information from the care givers at that instance similarly, patients that have waited for long hours before being attended to are likely to be upset by a provider who was using smartphone to get information rather than attending to the patient. The use of mobile devices by healthcare providers during such clinical encounters would be perceived by many patients to reflect a lack of professionalism.

Furthermore, one fifth of the patients in the present study, are of the opinion that use of smartphone by health care professionals in front of patients in the clinic is an indication that such professionals is ignorant of what to do and as such care of patients should not be entrusted into their hands. This showed that patients' confidence can be lost in patients-providers relationship. A similar observation was made by Brandt et $\mathrm{al}^{22}$ that improper use of smartphones by healthcare providers during duty could raise professional concerns such as poor professional image due to using the phone in the presence of a patient and therefore precautions such as "not using the apps in the presence of the patients" should be adhered to while in the clinic.

The result also revealed that, there was no association between the age of patients, educational qualification and their perception on usage of smartphones for health care information among health care professionals. This showed that, age and educational status of patients in this study did not influenced their perception on the use of smartphones for medical information by health care professionals during clinic hours.

\section{CONCLUSIONS}

Patients in this study demonstrated high level of awareness on the usage of smartphones for personal medical information and its usage by health care professional for health care information in the management of patients for better result. Although, 


\section{Perception of Patients on Usage of Smartphones by Health Care Professionals during Clinic Hours}

majority of the patients in this study did not perceive the use of smartphone for medical information during clinical hour by health care professionals unprofessional however, the usage of smartphones by health care professionals in front of patients during clinic hours should be done with caution and patients' education on the usefulness of such practise in order to gain the confidence and preserve good rapport of the few patients in the population that perceived such practise unprofessional.

Table 1: Demographic characteristics of respondents

\begin{tabular}{|c|c|c|}
\hline VARIABLES (N-185) & $\mathbf{n}$ & $\%$ \\
\hline \multicolumn{3}{|l|}{ Age group (Years) } \\
\hline $16-25$ & 28 & 15.1 \\
\hline $26-35$ & 49 & 26.5 \\
\hline $36-45$ & 31 & 16.8 \\
\hline $46-55$ & 25 & 13.5 \\
\hline $56-65$ & 19 & 10.3 \\
\hline $66-75$ & 25 & 13.5 \\
\hline $76-85$ & 6 & 3.2 \\
\hline $86-95$ & 2 & 1.1 \\
\hline \multicolumn{3}{|l|}{ Sex } \\
\hline Male & 76 & 41.1 \\
\hline Female & 109 & 58.9 \\
\hline \multicolumn{3}{|l|}{ Marital status } \\
\hline Single & 42 & 22.7 \\
\hline Married & 125 & 67.6 \\
\hline Divorced & 0 & 0.0 \\
\hline Widow & 15 & 8.1 \\
\hline widower & 3 & 1.6 \\
\hline \multicolumn{3}{|l|}{ Educational Qualification } \\
\hline No Formal Education & 0 & 0.0 \\
\hline Primary & 29 & 15.7 \\
\hline Secondary & 42 & 22.7 \\
\hline Tertiary & 114 & 61.6 \\
\hline \multicolumn{3}{|l|}{ Location } \\
\hline Federal Teaching Hospital, Ido- Ekiti & 64 & 34.6 \\
\hline Federal Medical Centre, Owo & 121 & 65.4 \\
\hline \multicolumn{3}{|l|}{ Clinic } \\
\hline Medical Outpatient & 50 & 27.0 \\
\hline Surgical Outpatient & 26 & 14.1 \\
\hline Orthopeadic Outpatient & 25 & 13.5 \\
\hline Physiotherapy Outpatient & 42 & 22.7 \\
\hline Opthalmology Outpatient & 31 & 16.8 \\
\hline Obstetric /Gyneacology Outpatient & 11 & 5.9 \\
\hline
\end{tabular}

Table 2: Perception of respondents on the use of smartphones for medical related information

\begin{tabular}{|c|c|c|}
\hline \multirow[t]{2}{*}{ Variables } & Yes & No \\
\hline & $(\%)$ & $(\%)$ \\
\hline I do own a smartphone & $125(67.6)$ & $60(32.4)$ \\
\hline Have search for health related information on smartphones & $67 \quad(32.6)$ & $118(63.8)$ \\
\hline $\begin{array}{l}\text { Have seen health care provider browsing for information while attending to me } \\
\text { in the clinic }\end{array}$ & $64 \quad(34.6)$ & $121(65.4)$ \\
\hline $\begin{array}{l}\text { My health care provider explain to me why he was browsing for information } \\
(\mathrm{N}=64)\end{array}$ & $18(28.1)$ & $46(71.9)$ \\
\hline
\end{tabular}


Perception of Patients on Usage of Smartphones by Health Care Professionals during Clinic Hours

\begin{tabular}{|c|c|c|c|}
\hline Smartphones can be helpful in Patient's care & $146(78.9)$ & $29(15.7)$ & $10(5.4)$ \\
\hline $\begin{array}{l}\text { There are various smartphone - Apps that can be used in patient } \\
\text { care }\end{array}$ & $104(56.2)$ & $63(34.1)$ & $18(9.7)$ \\
\hline $\begin{array}{l}\text { Use of smartphone by health care providers while attending to } \\
\text { patients in the clinic is unprofessional }\end{array}$ & $63(34.1)$ & $60(32.4)$ & $62(33.5)$ \\
\hline $\begin{array}{l}\text { Use of smartphone by health care providers while attending to } \\
\text { patients in the clinic is an indication that he/she does not know } \\
\text { what to do. }\end{array}$ & $39(21.1)$ & $51(27.6)$ & $95(51.4)$ \\
\hline $\begin{array}{l}\text { I will not entrust my care to a health care providers with such } \\
\text { practises }\end{array}$ & $43(23.2)$ & $38(20.5)$ & $104(56.2)$ \\
\hline I do not have confidence in such health care providers & $43(23.2)$ & $33(17.8)$ & 109 (58.9) \\
\hline $\begin{array}{l}\text { If he/she explain to me the reason for using his/her smartphone, } \\
\text { I will still not have confidence in him/her. }\end{array}$ & $63(34.1)$ & $36(19.5)$ & $86(46.5)$ \\
\hline
\end{tabular}

Table 3: Association between respondents' age, educational qualification and responses to use of smartphones

\begin{tabular}{|c|c|c|c|c|c|}
\hline \multirow{2}{*}{$\begin{array}{l}\text { Variables } \\
\text { Age Group }\end{array}$} & \multicolumn{3}{|c|}{ Usage of smartphone during clinic is unprofessional } & \multirow[t]{2}{*}{$x 2$} & \multirow[t]{2}{*}{ p value } \\
\hline & Agree & Undecided & Disagree & & \\
\hline $16-25$ years & $7(25.0)$ & $9(32.1)$ & $12(42.9)$ & & \\
\hline 26-35 & $14(28.6)$ & $15(30.6)$ & $20(40.8)$ & & \\
\hline $36-45$ & $12(38,7)$ & $10(32.3)$ & $9(29.0)$ & & \\
\hline 46-55 & $11(44.0)$ & $7(28.0)$ & $7(28.0)$ & 12.00 & 0.606 \\
\hline $56-65$ & $10(52.6)$ & $4(21.1)$ & $5(26.3)$ & & \\
\hline $66-75$ & $7(28-0)$ & $12(48.0)$ & $8(24.0)$ & & \\
\hline 76-85 & $1(10.7)$ & $3(50.0)$ & $2(33.3)$ & & \\
\hline $86-95$ & $1(50.0)$ & $0(0.0)$ & $1(50.0)$ & & \\
\hline \multicolumn{6}{|l|}{$\begin{array}{l}\text { Educational } \\
\text { qualification }\end{array}$} \\
\hline Primary & 7 (24.1) & 15 (51.7) & 7 (24.1) & & \\
\hline Secondary & $11(28.2)$ & $13(31.0)$ & 18(42.9) & 8.501 & 0.075 \\
\hline Tertiary & 45 (39.5) & $32(28.1)$ & $37(32.5)$ & & \\
\hline
\end{tabular}

Figure 1. A bar chart showing the distribution of responses by age group to "Use of smartphone by health care providers while attending to patients in the clinic is unprofessional"

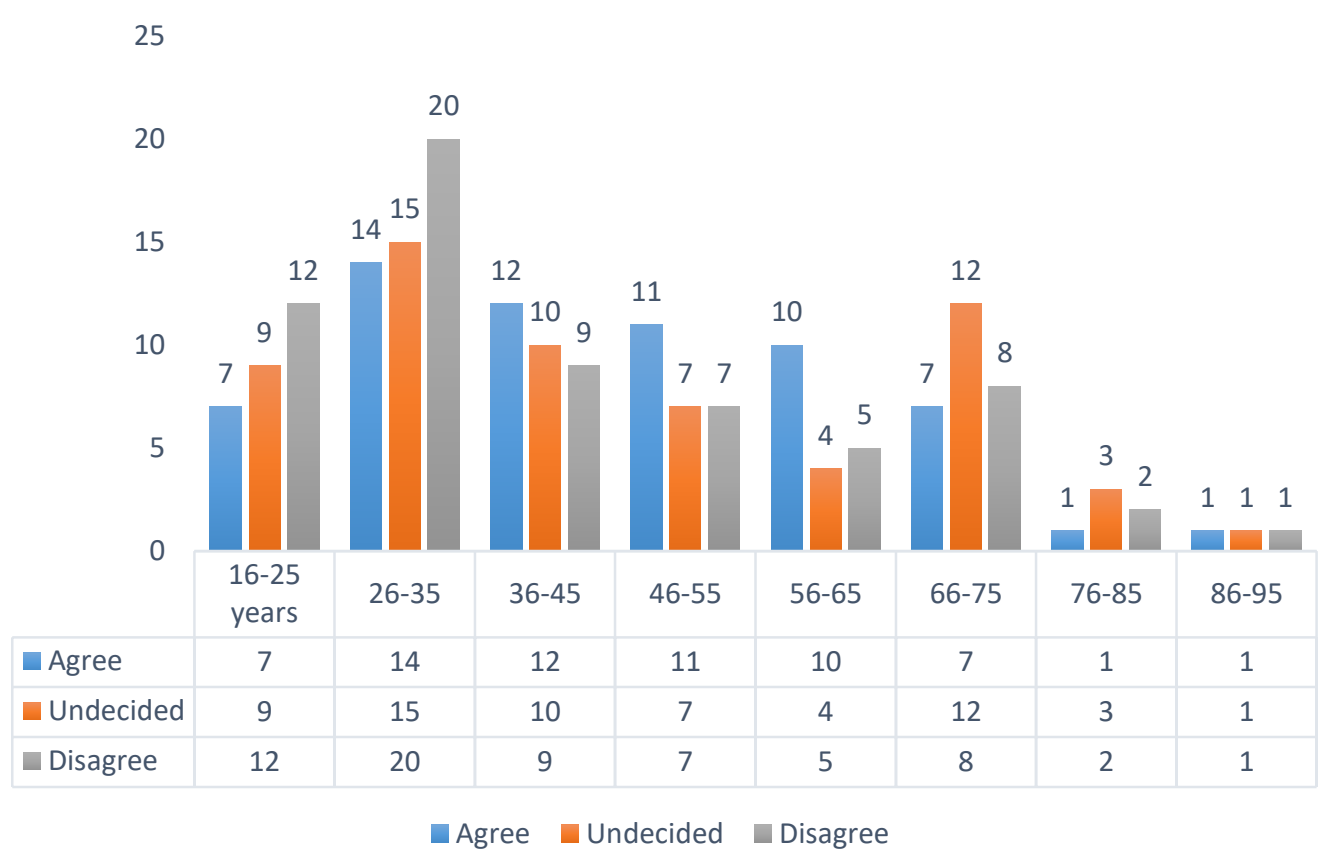




\section{Perception of Patients on Usage of Smartphones by Health Care Professionals during Clinic Hours}

Figure 2. A bar chart showing the distribution of responses by educational qualification to "Use of smartphone by health care providers while attending to patients in the clinic is unprofessional"

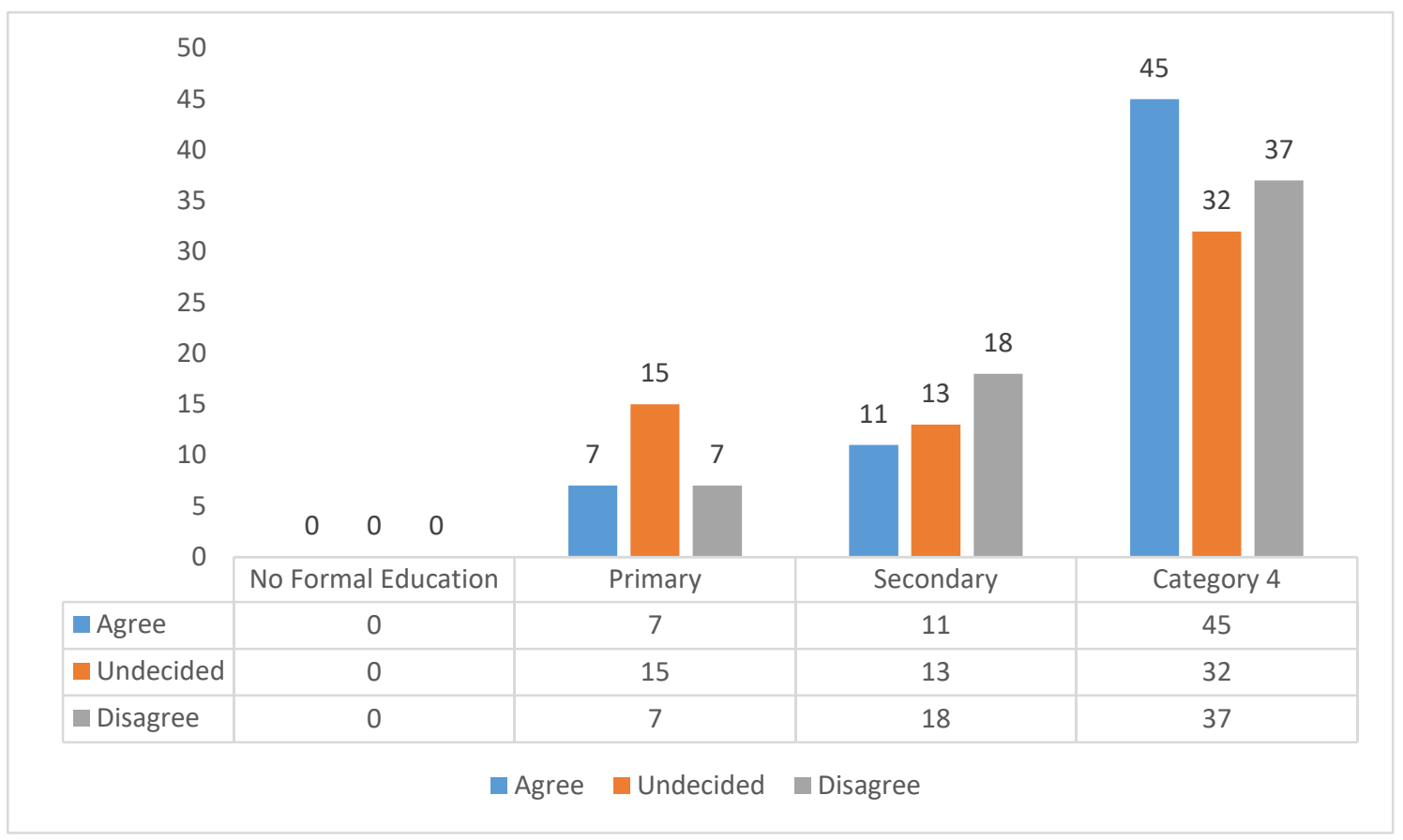

\section{REFERENCES}

1) Boulos $M N K$, Wheeler $S$, Tavares $C$, et al. How smartphones are changing the face of mobile and participatory healthcare: an overview, with example from eCAALYX. Biomed Eng Online 2011;10: 24-14.

2) Pew Research Center. The Future of Apps and Web. Available at: http://www.pewinternet.org/2012/03/23/the-futureof-apps-and-web/. Accessed on September 6, 2015.

3) World Health Organization. mHealth: New horizons for health through mobile technologies. Available at:http://www.who.int/goe/publications/goe mhealth web. pdf. Accessed on September 6, 2015.

4) Goldbach $\mathrm{H}$, Chang $\mathrm{AY}$, Kyer A, et al. Evaluation of generic medical information accessed via mobile phones at the point of care in resource-limited settings. J Am Med Inform Assoc 2014; 21(1): 37-42.

5) Hussain M, Al-Haiqi A, Zaidan AA, et al. The landscape of research on smartphone medical apps: coherent taxonomy, motivations, open challenges and recommendations. Comput Meth Prog Biomed 2015; 122(3): 393-408.

6) Mosa AS, Yoo I and Sheets L. A systematic review of healthcare applications for smartphones. BMC Med Inform Decis Mak 2012; 12: 67-6947.

7) Payne KB, Wharrad $\mathrm{H}$ and Watts K. Smartphone and medical related App use among medical students and junior doctors in the United Kingdom (UK): a regional survey. BMC Med Inform Decis Mak 2012; 12: 121-6947.

8) Ozdalga $\mathrm{E}$, Ozdalga $\mathrm{A}$ and Ahuja $\mathrm{N}$. The smartphone in medicine: a review of current and potential use among physicians and students. J Med Internet Res 2012; 14(5): e128.

9) Putzer GJ and Park Y. Are physicians likely to adopt emerging mobile technologies? Attitudes and innovation actors affecting smartphone use in the Southeastern United States. Perspect Health Inf Manag 2012; 9: 1 b.

10) Ventola C. Mobile devices and apps for health care professionals: uses and benefits. P \& T 2014 May;39(5):356-364 [FREE Full text] [Medline: 24883008]

11) Mostaghimi A, Crotty BH. Professionalism in the digital age. Ann Intern Med 2011 Apr 19;154(8):560-562. [doi:10.7326/0003-4819-154-8-201104190-00008] [Medline: 21502653]

12) Franko OI, Tirrell TF. Smartphone app use among medical providers in ACGME training programs. J Med Syst 2012 Oct

13) Strayer SM, Semler MW, Kington ML, Tanabe KO. Patient attitudes toward physician use of tablet computers in the exam room. Fam Med 2010 Oct;42(9):643-647 [FREE Full text] [Medline: 20927673]

14) Rudkin SE, Langdorf MI, Macias D, Oman JA, Kazzi AA. Personal digital assistants change management more often than paper texts and foster patient confidence. Eur J Emerg Med 2006 Apr;13(2):92-96.

[doi:10.1097/01.mej.0000192049.04729.0c] [Medline: 16525237] 


\section{Perception of Patients on Usage of Smartphones by Health Care Professionals during Clinic Hours}

15) Houston T, Ray M, Crawford M, Giddens T, Berner E. Patient perceptions of physician use of handheld computers. AMIA Annu Symp Proc 2003:299-303 [FREE Full text] [Medline: 14728182]

16) Georgina Kerry,; Shyam Gokani; Dara Rasasingam; Alexander Zargaran;Javier Ash; Aaina Mittal: 2017:Patient perception of smartphone usage bydoctors Smart Homecare Technology and TeleHealth https://www.dovepress.com/ by 105.112.106.50

17) Statista. UK Smartphone Ownership by Age from 2012-2016. Available from: https://www.statista.com/statistics/271851/smartphone-owners-in-the-united-kingdom-uk-by-age/.। Accessed September 19, 2016

18) Alvin Chan, , Richard Kow, , , Jennifer K. Cheng, Adolescents' Perceptions on Smartphone Applications (Apps) For Health Management Journal of mobile technology in medicine 6:2:47_55, 2017 doi:10.7309/jmtm.6.2.6

19) Alameddine M, Tamim H, Hadid D, Cheaito MA, Makki M, Maatouk H, Hitti E Patient Attitudes Toward Mobile Device Use by Health Care Providers in the Emergency Department: Cross-Sectional Survey JMIR Mhealth Uhealth 2020;8(3):e16917 doi: $10.2196 / 16917$

20) Kaczmarek BF, Trinh Q, Menon M, Rogers CG. Tablet telerounding. Urology 2012 Dec;80(6):1383-1388. [doi: 10.1016/j.urology.2012.06.060] [Medline: 23206790]

21) Nair AG, Potdar NA, Dadia S, Aulakh S, Ali MJ, Shinde CA. Patient perceptions regarding the use of smart devices formedical photography: results of a patient-based survey. Int Ophthalmol 2019 Apr 6;39(4):783-789. [doi: 10.1007/s10792-018-0878-2] [Medline: 29511959]

22) Brandt J, Katsma D, Crayton D, Pingenot A. Calling in at work: An acute care nursing cellphone policies. Nurs Manage 2016; 47: 20-7 